\title{
Infective endocarditis requiring ICU admission: epidemiology and prognosis
}

\author{
Olivier Leroy ${ }^{1 *}$, Hugues Georges ${ }^{1}$, Patrick Devos ${ }^{2}$, Steve Bitton ${ }^{3}$, Nathalie De Sa ${ }^{4}$, Céline Dedrie ${ }^{5}$, \\ Sébastien Beague ${ }^{6}$, Pierre Ducq ${ }^{7}$, Claire Boulle-Geronimi ${ }^{8}$, Damien Thellier ${ }^{1}$, Fabienne Saulnier ${ }^{3}$ \\ and Sebastien Preau ${ }^{3}$
}

\begin{abstract}
Background: Very few studies focused on patients with severe infective endocarditis (IE) and multiple complications leading to Intensive Care Unit (ICU) admission. Studied primary outcomes depended on the series and multiple prognostic factors have been identified. Our goal was to determinate characteristics of patients, in-hospital mortality and independent prognostic factors in an overall population of patients admitted to ICU for a left-sided, definite, active and severe IE.
\end{abstract}

Methods: Retrospective study performed in 9 ICUs during an 11-year period.

Results: Data of 248 patients (mean age $=62.4 \pm 13.3$ years; $63.7 \%$ male) were studied. Native and prosthetic valves were involved in 195 and 53 patients, respectively. Causative pathogens, identified in 225 patients, were mainly streptococci (45.6\%) and staphylococci (43.4\%). On ICU admission, 127 patients exhibited extra-cardiac involvement. Ninety-five patients had one or more neurological complications, as followed: ischemic stroke $(n=66)$, cerebral hemorrhage $(n=31)$, meningitis $(n=16)$, brain abscess $(n=16)$, and intracranial mycotic aneurysm $(n=10)$. Criteria prompting to cardiac surgery appeared during ICU stay for 186 patients and between ICU and hospital discharges in 5 patients. Due to contra-indications, surgery required by IE was only performed during hospitalization in 125 patients. Moreover, surgery was considered adequate according to usual guidelines in 76 of 191 patients with indication(s) of valvular surgery: for patients with surgical procedure considered as emergency $(n=69), 17$ surgical procedures underwent within the first $24 \mathrm{~h}$ following indication; for patients with urgent surgical indication $(n=102)$, surgery was performed during the first week following indication in 40 patients; finally, elective surgery $(n=20)$ was performed for 19 patients. During hospitalization, 103 (41.5\%) patients died. Four independent prognostic factors were identified: SAPS II > 35 (AOR = 2.604; $95 \%$ Cl: 1.320-5.136; $p=0.0058)$, SOFA > 8 (AOR = 3.327; $95 \%$ Cl: 1.697-6.521; $p=0.0005)$, IE due to methicillin resistant Staphylococcus aureus ( $\mathrm{AOR}=4.981 ; 95 \% \mathrm{Cl}=1.433-17.306 ; p=0.0115$ ) and native IE (AOR $=0.345 ; 95 \% \mathrm{Cl}: 0.169-0.703 ; p=0.0034)$.

Conclusions: Mortality in patients admitted to ICU for left-sided IE remains high, especially in cases of endocarditis due to methicillin resistant Staphylococcus aureus, when organ failures occur and ICU scores are high.

Keywords: Critical care medicine, Infective endocarditis, Cardiac surgery, Infectious diseases, Prognostic

\section{Background}

The annual incidence of infective endocarditis (IE) in France at the beginning of the 21st century is around 33

\footnotetext{
*Correspondence: oleroy@ch-tourcoing.fr

1 Service de Réanimation Médicale et Maladies Infectieuses, Hôpital

Chatiliez, 135 rue du Président Coty, Tourcoing 59200, France

Full list of author information is available at the end of the article
}

cases per million inhabitants [1]. Despite advances in diagnosis and medico-surgical treatment, the in-hospital mortality rate remains high, since ranging from 15 to $22 \%[1-3]$. Most recent data underline that now Staphylococcus aureus is the most common cause of IE and that approximately $50 \%$ of patients underwent early valve replacement or repair $[2,3]$.

\section{Springer}

C 2015 Leroy et al. This article is distributed under the terms of the Creative Commons Attribution 4.0 International License (http://creativecommons.org/licenses/by/4.0/), which permits unrestricted use, distribution, and reproduction in any medium, provided you give appropriate credit to the original author(s) and the source, provide a link to the Creative Commons license, and indicate if changes were made. 
Many complications can arise during the evolution of IE. Some are inaugural, the others come as the diagnosis has already been raised. Most of them can justify the admission of the patient in intensive care unit (ICU). Unfortunately, very few studies focused on patients with severe IE and multiple complications leading to ICU admission [4-7]. Therefore, we conducted a multicenter retrospective analysis of all consecutive critical left-sided IE patients to determinate characteristics of patients, inhospital mortality and independent prognostic factors in the overall population.

\section{Patients and methods}

\section{Study design and patients}

In 9 ICUs of 7 hospitals (Boulogne sur Mer, Douai, Dunkerque, Valenciennes, Lille, Roubaix, and Tourcoing) in Nord-Pas de Calais, an area from North of France, the charts of all consecutive patients admitted to the ICU with a diagnosis of IE between January 2002 and December 2012 were reviewed (OL, HG, SBi, ND, CD, SBe, $\mathrm{PDu}, \mathrm{CBG}$ and SP). Information collected from medical records was anonymously entered into a database and reviewed for data entry errors and/or inconsistencies (OL, HG, SBi and SP). In agreement with French regulations concerning observational studies that do not modify existing diagnosis or therapeutic strategies, no ethics committee approval was required to conduct the study.

Adult patients were enrolled in the study if they had a left-sided, definite, active and severe IE requiring ICU admission. IE involving mitral and/or aortic valves was defined as left-sided. Patients with both left- and rightsided IE and left-sided IE associated with infection of a cardiac implantable electronic device (CIED) were considered as left-sided IE. Definite IE was defined according to modified Duke criteria [8]. Endocarditis was defined as active if the patient was admitted in ICU before or within the first 30 days of antimicrobial treatment. IE was considered as severe when associated with any of the following criteria: acute respiratory failure requiring mechanical ventilation, shock, Simplified Acute Physiology Score (SAPS) II $\geq 20$ and Sepsis-related Organ Failure Assessment (SOFA) score $\geq 3$.

Patients with right-sided IE or infection of a cardiac implantable electronic device without left valves involvement were not included as well as patients with IE acquired during ICU stay, or admitted in ICU after valve surgery for IE and, finally, those with possible IE.

\section{Data collection and definitions}

For each patient, IE was diagnosed when required modified Duke criteria were obtained. As all these criteria could not be present on ICU admission, there may be a delay between ICU admission and IE diagnosis that was determined. When IE was diagnosed, we collected for each patient information about demographics, preexisting comorbidities, condition at ICU admission, initial valve status, origin of infection, microbiological data, echocardiographic data, and extra-cardiac involvement revealed by initial work-up. As this study was retrospective, the initial work-up was not standardized and radiological examinations were performed at the discretion of physicians. During the ICU stay, the antimicrobial treatment, the occurrence of complications, indications for surgery, timing of surgical procedure were recorded. Finally, outcome was evaluated.

Underlying conditions were evaluated by the Charlson score [9]. Severity of illness at ICU admission was assessed by the SAPS II, and SOFA score [10, 11]. Prosthetic valve IE was defined as infection occurring on any type of tissue or mechanical device. Hospital-acquired IE was defined as infection occurring more than $72 \mathrm{~h}$ after admission to the hospital or acquired in association with a significant invasive procedure performed during a recent hospitalization within 8 weeks of this hospitalization [12]. Microbiological diagnosis was assessed according to modified Duke criteria. Echocardiographic data recorded were regurgitant valve, vegetation length and location. Follow-up examinations were performed to monitor vegetation size and to detect the occurrence of complications. Antimicrobial therapy was considered adequate if it included antibiotic(s) usually proposed by current guidelines [13]. IE complications on ICU admission such as congestive heart failure, septic shock, and extra-cardiac involvement mainly due to systemic embolic events were defined according to current guidelines [13]. For neurological involvement, five complications were distinguished according to the results of brain imaging (magnetic resonance imaging and/or computerized tomography scanning) and cerebrospinal fluid analyses performed on initial work-up: ischemic stroke, cerebral hemorrhage, meningitis or meningeal reaction, brain abscess, and intracranial mycotic aneurysm.

Indications (heart failure, prevention of embolic events and uncontrolled infection) and timing of surgery (emergency, urgent and elective) were defined by current guidelines [13]. Surgery was considered adequate when surgical procedure was performed accordingly to such guidelines. In-hospital mortality was defined as death occurring within the same hospitalization as ICU admission, regardless of its cause.

\section{Statistical analysis}

Descriptive analyses were performed to check and summarize the data. Quantitative variables are reported as mean \pm standard deviation. Qualitative variables are reported as number and percentage. Continuous 


\section{Table 1 Main patients' characteristics on ICU admission and on IE diagnosis}

\begin{tabular}{|c|c|}
\hline \multicolumn{2}{|l|}{ Patients' characteristics } \\
\hline Age (years) & $62.4 \pm 13.3$ \\
\hline Sex: M/F & $158 / 90$ \\
\hline Charlson score & $4.58 \pm 2.70$ \\
\hline SAPS $\|$ & $36.7 \pm 16.7$ \\
\hline SOFA score & $7.0 \pm 3.7$ \\
\hline \multicolumn{2}{|l|}{ Main indications for ICU admission } \\
\hline Septic shock & $54(21.8)$ \\
\hline Severe valvular regurgitation & $46(18.55)$ \\
\hline Cardiogenic shock & $39(15.7)$ \\
\hline Acute renal failure & $36(14.5)$ \\
\hline $\begin{array}{l}\text { Acute respiratory failure requiring mechanical } \\
\text { ventilation }\end{array}$ & $28(11.3)$ \\
\hline Neurological complications & $17(6.85)$ \\
\hline Community-acquired/hospital-acquired IE & $215(86.7) / 33(13.3)$ \\
\hline Native valve/prosthetic valve IE & $195(78.6) / 53(21.4)$ \\
\hline \multicolumn{2}{|l|}{ Valve involvement } \\
\hline Aortic & 156 \\
\hline Mitral & 152 \\
\hline Tricuspid & 9 \\
\hline Pulmonary & 1 \\
\hline Multiple valve involvement & 66 \\
\hline Aortic plus mitral valves & 53 \\
\hline Aortic plus tricuspid valves & 3 \\
\hline Aortic plus pulmonary valves & 1 \\
\hline Aortic plus mitral plus tricuspid valves plus CIED & 1 \\
\hline Aortic plus mitral valves plus CIED & 3 \\
\hline Aortic valve plus CIED & 1 \\
\hline Mitral plus tricuspid valves & 3 \\
\hline Mitral plus tricuspid valves plus CIED & 1 \\
\hline Portal of entry of IE & $126(50.8)$ \\
\hline Skin or soft tissue & 36 \\
\hline Dental & 24 \\
\hline Upper respiratory tract & 9 \\
\hline Genitourinary tract & 13 \\
\hline Digestive tract & 23 \\
\hline Intra-venous drug abuse & 2 \\
\hline Cardiovascular procedure or vascular access & 19 \\
\hline
\end{tabular}

The results are given as $n$ (\%) or median \pm SD

When indicated SAPS // Simplified Acute Physiologic Score II, SOFA sepsis-related organ failure assessment score, CIED cardiac implantable electronic device

variables were compared using the Student's t test. Categorical variables were compared using the Chi-square test or Fisher's exact test when Chi square was not appropriate. Differences between groups were considered to be significant for variables yielding a $p$ value $\leq 0.05$. A stepwise logistic regression analysis was performed to identify risk factors associated with in-hospital mortality, regardless of its cause. In order to identify independent risk factors for mortality, variables were included in the multivariate model if the $p$ value was $\leq 0.05$ in bivariate analysis. Adjusted odds ratios (AOR) were computed using logistic regression analysis including the independent predictors of mortality.

All statistical analyses were performed using SAS software, V9.1.

\section{Results}

During the study period, 352 patients with IE were admitted in one of the 9 ICUs of our group. We excluded 104 patients for the following reasons: right-sided IE or infection of a cardiac implantable electronic device without left valves involvement $(n=41)$; diagnosis of IE non definite $(n=34)$; non severe IE $(n=24)$; IE acquired during ICU stay $(n=5)$. Finally, 248 patients with severe, active, definite and left-sided IE were studied. Among them, two IE major criteria were present in 232 patients and one major criterion with 2 or 3 minor criteria was present in the remaining 16 patients. One hundred fortyeight $(59.7 \%)$ patients were admitted in a tertiary care hospital with a cardiac surgery department (Lille) and 100 (40.3\%) were admitted in a general hospital without any cardiac surgery department. The mean delay between ICU admission and IE diagnosis was $1.75 \pm 3.74$ days. Main patients' characteristics on ICU admission and on IE diagnosis are summarized in Table 1.

Echocardiographic examinations revealed mitral vegetation(s) in 137 patients. Vegetations were large $(>10 \mathrm{~mm})$ in 67 patients and very large $(>15 \mathrm{~mm})$ in 41 patients. Mitral regurgitation was severe ( 3 to $4+$ ) in 56 patients. One hundred and twenty-three patients exhibited aortic vegetation(s). They were large and very large in 51 and 24 patients, respectively. Aortic regurgitation was severe in 66 patients. An annular abscess was observed in 67 patients. Six patients had a pericardial effusion. Finally, the mean value of left ventricular ejection fraction was $55.0 \pm 11.6 \%$. It was $<35 \%$ in 16 patients, $>35 \%$ and $<50 \%$ in $82,>50 \%$ in 144 , and finally not determined in 6 .

Causative pathogen was identified in 225 (90.7 \%) patients. Blood and leaflet cultures were positive in 222 and 25 cases, respectively. Two hundred and thirty-five causative pathogens were identified. IE was polymicrobial in 9 patients. The most common pathogens were streptococci $(45.6 \%$ ), and staphylococci (43.4\%) (Table 2).

On ICU admission and during the initial course of IE, 127 patients (51.2 \%) exhibited extra-cardiac involvement. Main involved organ was the central nervous system. According to neurological investigations performed on 184 patients (74.2 \%) (computerized tomography scanning $n=160$, magnetic resonance imaging, 
Table 2 Causative microorganisms $(n=235)$ isolated from cases of active IE

\begin{tabular}{ll}
\hline Micro organism & $\mathbf{N}(\%)$ \\
\hline Streptococcus spp. & $107(45.6)$ \\
Beta-haemolytic Streptococcus (groups A, B, C and G) & 27 \\
Oral Streptococcus & 24 \\
Enterococcus spp. & 24 \\
Group D Streptococcus & 19 \\
Streptococcus pneumoniae & 13 \\
Staphylococcus aureus & $90(38.3)$ \\
Methicillin-susceptible & 74 \\
Methicillin-resistant & 16 \\
Coagulase-negative Staphylococcus & $12(5.1)$ \\
Gram-negative bacilli & $14(6.0)$ \\
Haemophilus influenzae & 2 \\
Enterobacteriaceae & 11 \\
Pasteurella multocida & 1 \\
Gram positive bacilli & $1(0.4)$ \\
Candida spp. and Aspergillus spp. & $4(1.7)$ \\
Other & $7(3.05)$ \\
\hline
\end{tabular}

and cerebrospinal fluid analyses $n=25), 139$ neurological complications were found in 95 patients, as followed: ischemic stroke $(n=66)$, cerebral hemorrhage $(n=31)$, meningitis $(n=16)$, brain abscess $(n=16)$, and intracranial mycotic aneurysm $(n=10)$. Moreover, according to chest $(n=105)$, bone $(n=75)$ and abdominal $(n=144)$ computerized tomography scans, abdominal ultrasonography $(n=34)$, lung $(n=8)$ and bone $(n=13)$ scans, and bone magnetic resonance imaging $(n=24)$, systemic embolic or metastatic infective events involving spleen $(n=33)$, bone and joints $(n=22)$, kidneys $(n=21)$, lung $(n=3)$ and liver $(n=3)$ were found.

All patients received an antimicrobial treatment. This treatment was adequate in $206(83.1 \%)$ patients. During ICU stay, surgery was indicated for $186(75 \%)$ patients. The timing of surgical procedure was considered as emergency in $69(37.1 \%)$ patients, urgent in $102(54.9 \%)$ patients and elective in $15(8 \%)$ patients. Main indications and contraindications for surgery are summarized in Table 3. Surgery was performed in 99 patients during the ICU stay (Table 4). Among the 101 patients without contra-indications to surgery, 84 (83.2 \%) patients underwent surgery during ICU stay. Among the 85 patients with contra-indications, surgery was nonetheless performed in 15 (17.6\%) patients. In these latter patients, contra-indications were hemorrhagic stroke $(n=10)$, multiple organ failure $(n=3)$ and severe underlying diseases $(n=2)$. It could be noticed that only two of them, exhibiting multiple organ failure, died. Moreover, 21 patients with surgery indicated during ICU stay and 5 patients with ultimately appeared indication underwent surgical procedure between ICU and hospital discharges. Thus, during hospitalization, a surgical procedure was required by IE in 191 patients and was performed for 125 patients. Surgical procedure was required more often for patients admitted in a tertiary care hospital with a cardiac surgery department $(n=127 / 148)$ than for admitted in a general hospital without any cardiac surgery department $(n=64 / 100)(p<0.001)$.

For patients with surgical procedure considered as emergency $(n=69), 17$ surgical procedure underwent within the first $24 \mathrm{~h}$ following indication. For patients with urgent surgical indication $(n=102)$, surgery was performed during the first week following indication in 40 patients. Finally elective surgery $(n=20)$ was performed for 19 patients. So, surgery was considered adequate according to usual guidelines in 76 of 191 (39.8\%) patients with indication(s) of valvular surgery. Surgery was more often adequate for patients admitted in a tertiary care hospital with a cardiac surgery department $(n=57 / 127)$ than for patients in a general hospital without any cardiac surgery department $(n=19 / 64)$ $(p<0.001)$.

Table 3 Main Indications and contra-indications for valvular surgery during ICU stay

\begin{tabular}{|c|c|c|c|}
\hline Timing of surgery & Indications & $\begin{array}{l}\text { Number of patients } \\
\text { with contra-indications }\end{array}$ & Contra-indications \\
\hline Emergency $n=69$ & $\begin{array}{l}\text { Cardiogenic shock } n=41 \\
\text { Refractory pulmonary oedema } n=28\end{array}$ & $33(47.8 \%)$ & $\begin{array}{l}\text { Multiple organ failure } n=16 \\
\text { Hemorrhagic stroke } n=8 \\
\text { Severe underlying diseases } n=7 \\
\text { Risk of extra cerebral hemorrhage } n=2\end{array}$ \\
\hline Urgent $n=102$ & $\begin{array}{l}\text { Very large vegetations }=43 \\
\text { Large vegetations and embolic episodes } \\
\quad n=21 \\
\text { Annular abscess } n=27 \\
\text { Uncontrolled infection } n=8 \\
\text { Severe acute regurgitation } n=3\end{array}$ & $50(49 \%)$ & $\begin{array}{l}\text { Risk of cerebral hemorrhage } n=22 \\
\text { Multiple organ failure } n=16 \\
\text { Severe underlying diseases } n=11 \\
\text { Risk of extra cerebral haemorrhage } n=1\end{array}$ \\
\hline Elective $n=15$ & $\begin{array}{l}\text { Severe regurgitation without heart failure } \\
\quad n=12 \\
\text { Severe prosthetic dehiscence } n=3\end{array}$ & $2(13.3 \%)$ & $\begin{array}{l}\text { Severe underlying diseases } n=1 \\
\text { Multiple organ failure } n=1\end{array}$ \\
\hline
\end{tabular}


Table 4 In hospital mortality according to surgery during ICU stay and in-hospital mortality

\begin{tabular}{|c|c|c|c|c|c|}
\hline $\begin{array}{l}\text { Timing } \\
\text { of surgery }\end{array}$ & $\begin{array}{l}\text { Number } \\
\text { of patients }\end{array}$ & $\begin{array}{l}\text { Number of patients } \\
\text { with surgery performed } \\
\text { during ICU stay }\end{array}$ & $\begin{array}{l}\text { In hospital } \\
\text { mortality } n(\%)\end{array}$ & $\begin{array}{l}\text { Number of patients } \\
\text { with surgery not } \\
\text { performed during ICU stay }\end{array}$ & $\begin{array}{l}\text { In hospital } \\
\text { mortality } n(\%)\end{array}$ \\
\hline \multicolumn{6}{|c|}{ Patients with contra-indications to surgery $n=85$} \\
\hline Emergency & 33 & 6 & $1(16.7 \%)$ & 27 & $25(92.6 \%)$ \\
\hline Urgent & 50 & 8 & $1(12.5 \%)$ & 42 & $30(71.4 \%)$ \\
\hline Elective & 2 & 1 & 0 & 1 & 0 \\
\hline \multicolumn{6}{|c|}{ Patients without contra-indications to surgery $n=101$} \\
\hline Emergency & 36 & 36 & $6(16.6 \%)$ & 0 & 0 \\
\hline Urgent & 52 & 41 & $11(21.2 \%)$ & 11 & 0 \\
\hline Elective & 13 & 7 & 0 & 6 & $2(33.3 \%)$ \\
\hline
\end{tabular}

During hospitalization, 103 (41.5\%) patients died. Main significant factors associated with in-hospital mortality in bivariate analysis are reported in Table 5 . Factors assessing severity of underlying diseases and/or IE on ICU admission were associated with a significant increased mortality as well as prosthetic and staphylococcal IE. Conversely, native IE, IE due to Streptococcus and therapeutic measures such as surgery during ICU stay, adequate surgery and adequate antimicrobial treatment were associated with a significant decreased mortality. Multivariate analysis including all significant variables in bivariate analysis $(p<0.05)$, except surgery during ICU stay, surgery (overall) and adequate surgery, identified 4 independent prognostic factors. They were SAPS II > 35 (AOR $=2.604 ; 95 \%$ CI: $1.320-5.136 ; p=0.0058)$, SOFA > 8 (AOR = 3.327; $95 \%$ CI: $1.697-6.521 ; p=0.0005)$, IE due to methicillin resistant Staphylococcus aureus $(\mathrm{AOR}=4.981$; $95 \% \mathrm{CI}=1.433-17.306 ; p=0.0115)$ and native valve IE $(\mathrm{AOR}=0.345 ; 95 \% \mathrm{CI}: 0.169-0.703 ; p=0.0034)$.

To focus on the 16 patients with IE due to methicillin resistant Staphylococcus aureus, we could add that 12 had a native valve IE. Infection was hospital-acquired in 8 cases. Main portal of entry were skin or soft tissue $(n=4)$ and vascular access infections $(n=4)$. On ICU admission, the mean SAPS II was $44.6 \pm 23.7$ and 7 patients exhibited septic shock. Annular abscess was observed in 7 patients and neurological complications occurred in 7 patients. Antimicrobial treatment was considered inadequate in 4 patients (vancomycin without gentamicin in 2 cases of native valve IE and vancomycin + gentamicin without rifampin in 2 cases of prosthetic valve IE). Surgery was indicated for 11 patients (emergency $n=3$; urgent $n=7$; elective $n=1$ ) but was adequate in only 3 patients. During hospitalization, 12 patients died (in ICU, $n=10$ ).

\section{Discussion}

We report the results of a retrospective multicenter study on 248 patients with severe, active, definite and left-sided
IE requiring ICU admission. Main causative pathogens are equally represented by streptococci and staphylococci. During ICU stay, surgery was indicated for $75 \%$ of patients but only $53 \%$ of them underwent surgical procedures during ICU stay. Overall in-hospital mortality was $41.5 \%$. Independent factors associated with prognosis were SAPS II on ICU admission $>35$, SOFA on ICU admission $>8$, IE due to methicillin resistant Staphylococcus aureus and native IE.

Current data suggest that staphylococci are the most common causative pathogens of IE. In the overall population of adults with definite IE admitted to hospital, $S$. aureus accounted for 26.6-36.2 \% of causal agents [2, $14]$. In series including only adult patients admitted to ICU with infective endocarditis, $S$. aureus represented 45-56\% of identified causative organisms [4, 7]. Our results could appear surprising since even if staphylococci are involved in $43.4 \%$ of patients, they are less frequent causative organisms than streptococci involved in $45.6 \%$ of patients. However, they are similar to those reported more than 10 years ago by Hoen et al. in France and Hasbun et al. in USA $[15,16]$. In these series having included patients in 1999 and between 1990 and 2000, streptococci are involved in 48 and $58 \%$, respectively. We have no clear explanation about these microbiological differences between our study and those reporting data from patients admitted in ICU [4, 7]. Nevertheless, studied patients could be a little different. In the study from Mourvillier and colleagues, prosthetic valve IE are more frequent than in our series (40.6 vs. $21.4 \%$ ) and, if we focused only on native IE, streptococci and staphylococci are equally involved as causative organisms [4]. In the study reported by Samol and colleagues, $31 \%$ of patients had right-sided endocarditis and it is well known that $S$. aureus is then the most common pathogen [7, 17].

In our study, a surgical procedure required by IE was performed during hospitalization for 125 patients (50.4\%). In series focusing on patients admitted to ICU 
Table 5 Bivariate analysis of risk factors for in-hospital mortality

\begin{tabular}{|c|c|c|c|}
\hline Factor & Survivors $n=145$ & Non-survivors $n=103$ & $p$ \\
\hline Charlson score & $4.18 \pm 2.80$ & $5.15 \pm 2.46$ & 0.003 \\
\hline SAPS $\|$ & $30.99 \pm 13.16$ & $44.60 \pm 17.95$ & $<0.0001$ \\
\hline SAPS $\|>35$ & $43(38.4 \%)$ & $69(61.6 \%)$ & $<0.0001$ \\
\hline SOFA score & $5.65 \pm 2.77$ & $8.93 \pm 3.91$ & $<0.0001$ \\
\hline SOFA score $>8$ & $30(33 \%)$ & $61(67 \%)$ & $<0.0001$ \\
\hline Glasgow Coma Score $<9$ & $7(17.9 \%)$ & $32(82.1 \%)$ & $<0.0001$ \\
\hline ICU admission for septic shock & $17(31.5 \%)$ & $37(68.5 \%)$ & $<0.0001$ \\
\hline ICU admission for cardiogenic shock & $16(41 \%)$ & $23(59 \%)$ & 0.016 \\
\hline ICU admission for acute respiratory failure & $22(78.6 \%)$ & $6(21.4 \%)$ & 0.02 \\
\hline ICU admission for severe valvular regurgitation & $40(87 \%)$ & $6(13 \%)$ & $<0.0001$ \\
\hline Mitral IE & $80(52.6 \%)$ & $72(47.4 \%)$ & 0.02 \\
\hline Native IE & $121(62.05 \%)$ & $74(37.95 \%)$ & 0.03 \\
\hline Prosthetic IE & $24(45.3 \%)$ & $29(54.7 \%)$ & 0.03 \\
\hline Annular abscess & $31(46.3 \%)$ & $36(53.7 \%)$ & 0.02 \\
\hline Severe aortic regurgitation & $50(75.8 \%)$ & $16(24.2 \%)$ & 0.0009 \\
\hline Left ventricular ejection fraction (\%) & $57 \pm 11$ & $52 \pm 13$ & 0.005 \\
\hline IE due to Streptococcus spp. & $72(67.3 \%)$ & $35(32.7 \%)$ & 0.01 \\
\hline IE due to MSSA & $36(48.70 \%)$ & $38(51.3 \%)$ & 0.04 \\
\hline IE due to MRSA & $4(25 \%)$ & $12(75 \%)$ & 0.005 \\
\hline Adequate antimicrobial treatment & $127(61.7 \%)$ & $79(38.3 \%)$ & 0.02 \\
\hline Surgery during ICU stay & $80(80.8 \%)$ & $19(19.2 \%)$ & $<0.0001$ \\
\hline Surgery (overall) & $102(81.6 \%)$ & $23(18.4 \%)$ & $<0.0001$ \\
\hline Adequate surgery & $65(85.5 \%)$ & $11(14.5 \%)$ & $<0.0001$ \\
\hline
\end{tabular}

MSSA methicillin-susceptible Staphylococcus aureus, MRSA methicillin-resistant Staphylococcus aureus

for IE, 35-52\% of patients underwent surgery [4, 6, 7]. Rather than these gross percentages, an important point is, in our mind, the percentage of performed surgical procedures among patients for which indications for surgery emerge during ICU stay. Literature data are unfortunately scarce. In our series, surgery was indicated for 186 (75\%) patients but only 99 (53\%) of them underwent surgical procedures during ICU stay. In the study reported by Mirabel et al., the percentage appears higher since 100 of 158 patients with recommended surgical procedure underwent surgery [6]. Unfortunately, in this series, the timing of surgical procedure (emergency, urgent and elective) was only reported for patients undergoing surgery. So, it was not possible to determine the adequacy of surgery according to the timing, and consequently, to compare these results with ours. It's a shame because it would have been interesting to known if the low percentage of adequate surgery observed in our series when timing was considered as emergency or urgent was also observed in other studies. In our series, it could be also noticed that among the 85 patients with contra-indications to surgery, 15 underwent nonetheless surgery and that 13 of them survived. Finally, surgery was more often adequate for patients admitted in a tertiary care hospital with a cardiac surgery department than for patients in a general hospital without any cardiac surgery department. Such a result reinforces recent recommendations for referring complicated IE patients to tertiary care hospitals in which a collaborative approach of IE involving notably a cardiac surgeon is possible [18].

The impact of surgery on IE prognosis was the subject of numerous studies. Despite some conflicting results, surgical therapy appears most often associated with an improved early and late survival both in the overall population of patients than in patients admitted to $\operatorname{ICU}[4,6$, 7, 19-25]. In our series, in-hospital mortality was $41.5 \%$. In similar series, mortality rates varied between 30 and $45 \%$, and apart surgery, identified independent prognostic factors were septic shock, cerebral emboli, immunosuppression, neurological failure, severe comorbidities, S. aureus IE and SAPS II [4, 5, 7]. Most of these factors appear in our series as significant prognostic factors in bi variate analysis. Among them, we could notice that IE due to Streptococcus spp. were associated with a lower mortality than IE due to Staphylococcus spp. and that adequacy of antimicrobial and of surgical treatment also appeared as factors associated with survival. However, in our study, we willingly chose to not enter in multivariate 
analysis the significant factors about surgery identified in bivariate analysis (surgery during ICU stay, surgery and adequate surgery) since the overall population was not affected by these prognostic factors. Our multivariate analysis identified 4 independent factors. They were SAPS II $>35($ AOR $=2.604)$, SOFA $>8($ AOR $=3.327)$, IE due to methicillin resistant Staphylococcus aureus $(\mathrm{AOR}=4.981)$ and native IE $(\mathrm{AOR}=0.345)$. The fact that scores assessing severity and/or organ failure on ICU admission are independent prognostic factors is not surprising since they are usually found in all studies focusing on prognostic of ICU patients. The protective role of the native character of endocarditis is not, in our opinion, surprising since the deleterious role of the prosthetic character of endocarditis is well known [3]. In example, in the study reported by Murdoch et al. including 2781 patients from the International Collaboration on Endocarditis-Prospective Cohort Study, prosthetic valve involvement appears as an independent factor associated with mortality [2]. The deleterious role of an infection due to methicillin-resistant Staphylococcus aureus could appear more surprising since it has not yet been found in previous studies. However, in our opinion, it was not really studied. In the study reported by Murdoch, 869 patients exhibited a $S$. aureus IE but no data about sensitivity to methicillin was reported [2]. In a French study reporting data about 497 adults with Duke-Li-definite IE, 180 patients had a S. aureus IE [14]. Resistance to methicillin was observed in $13.6 \%$ of $S$. aureus. Unfortunately, no data about impact of resistance to methicillin were provided. Finally, to the best of our knowledge, the study reported by Fowler et al. is one of the few studies providing prognostic data according to sensitivity to methicillin of S. aureus [26]. Among 1779 patients from the International Collaboration on Endocarditis-Prospective Cohort Study, the authors identified 424 patients with definite $S$ aureus IE and no history of active IDU. Among them, 141 (33.3\%) were infected with methicillin resistant $S$. aureus. These patients tended to have higher mortality ( 29.8 vs. $23.3 \% ; p=0.14$ ) than those infected with a methicillin susceptible strain.

Our study has several limitations. First, all data were collected retrospectively. Second, it was a multicenter study. As a consequence of these 2 points, diagnostic methods, screening for complications and therapeutic measures were not standardized. Moreover, only one of the seven hospitals participating in the study had cardiac surgery units. It could thus be assumed that the access to cardiac surgery has not been the same for all patients, the most distant patients from surgical units being the least likely to benefit from emergency or urgent surgery. Similarly, a multidisciplinary approach could not be optimal for these later patients. Third, independent prognostic factors were identified by a stepwise logistic regression analysis. No case-control analysis was performed to evaluate the performance of identified factors. Fourth, our analysis was unable to establish a causal relationship between some therapeutic measures such as adequate antimicrobial treatment and survival. In a previous work, we demonstrated that such a treatment was an independent prognostic factor associated with survival [27]. Finally, we have only information on in-hospital mortality and long-term outcome was unknown.

In conclusion, mortality in patients admitted to ICU for left-sided IE remains high, especially in cases of endocarditis due to methicillin resistant Staphylococcus aureus and when organ failures occur and ICU scores are high.

\section{Abbreviations}

AOR: adjusted odds ratios; Cl: confident interval; CIED: cardiac implantable electronic device; IE: infective endocarditis; ICU: intensive care unit; MSSA: methicillin-susceptible Staphylococcus aureus; MRSA: methicillin-resistant Staphylococcus aureus; SAPS II: simplified acute physiology score II; SD: standard deviation; SOFA: sequential organ failure assessment.

\section{Authors' contributions}

FS and SP designed the study. OL, HG, SBi, ND, CD, SBe, PDu, CBG and SP collected data. PDe analyzed the data. OL, DT and SP wrote the article. All authors read and approved the final manuscript.

\section{Author details}

1 Service de Réanimation Médicale et Maladies Infectieuses, Hôpital Chatiliez, 135 rue du Président Coty, Tourcoing 59200, France. ${ }^{2}$ Département de bio statistique, CHU de Lille, 59037 Lille Cedex, France. ${ }^{3}$ Pôle de Réanimation, Hôpital R. Salengro, CHU de Lille, Avenue du Professeur E. Laine, 59037 Lille Cedex, France. ${ }^{4}$ Service de Réanimation Polyvalente, Centre Hospitalier Jean Bernard, Avenue Désandrouin, 59322 Valenciennes Cedex, France. ${ }^{5}$ Service de Réanimation Polyvalente, Hôpital Victor Provost, Rue de Barbieux, 59056 Roubaix Cedex, France. ${ }^{6}$ Service de Réanimation Polyvalente, Centre Hospitalier de Dunkerque, Avenue Louis Herbeaux, 59385 Dunkirk, France. ${ }^{7}$ Service de Réanimation Polyvalente, Centre Hospitalier de Boulogne-surMer, Allée Jacques Monod, 62321 Boulogne-Sur-Mer Cedex, France. ${ }^{8}$ Service de Réanimation Polyvalente, Centre Hospitalier de Douai, Route de Cambrai, 59507 Douai Cedex, France.

\section{Competing interests}

The authors declare that they have no competing interests.

Received: 22 September 2015 Accepted: 17 November 2015

Published online: 01 December 2015

\section{References}

1. Duval X, Delahaye F, Alla F, Tattevin P, Obadia JF, Le Moing V, et al. Temporal trends in infective endocarditis in the context of prophylaxis guideline modifications: three successive population-based surveys. J Am Coll Cardiol. 2012. doi:10.1016/j.jacc.2012.02.029.

2. Murdoch DR, Corey GR, Hoen B, Miró JM, Fowler VG Jr, Bayer AS, et al. Clinical presentation, etiology, and outcome of infective endocarditis in the 21st century: the International Collaboration on EndocarditisProspective Cohort Study. Arch Intern Med. 2009. doi:10.1001/ archinternmed.2008.603.

3. Hoen B, Duval X. Infective endocarditis. N Engl J Med. 2013. doi:10.1056/ NEJMc1307282.

4. Mourvillier B, Trouillet JL, Timsit JF, Baudot J, Chastre J, Régnier B, et al. Infective endocarditis in the intensive care unit: clinical spectrum and 
prognostic factors in 228 consecutive patients. Intensive Care Med. 2004. doi:10.1007/s00134-004-2436-9.

5. Sonneville R, Mirabel M, Hajage D, Tubach F, Vignon P, Perez P, et al. Neurologic complications and outcomes of infective endocarditis in critically ill patients: the ENDOcardite en REAnimation prospective multicenter study. Crit Care Med. 2011. doi:10.1097/CCM.0b013e3182120b41.

6. Mirabel M, Sonneville R, Hajage D, Novy E, Tubach F, Vignon P, et al. Longterm outcomes and cardiac surgery in critically ill patients with infective endocarditis. Eur Heart J. 2014. doi:10.1093/eurheartj/eht303.

7. Samol A, Kaese S, Bloch J, Görlich D, Peters G, Waltenberger J, et al. Infective endocarditis on ICU: risk factors, outcome and long-term follow-up. Infection. 2015. doi:10.1007/s15010-014-0715-0.

8. Li JS, Sexton DJ, Mick N, Nettles R, Fowler VG Jr, Ryan T, et al. Proposed modifications to the Duke criteria for the diagnosis of infective endocarditis. Clin Infect Dis. 2000;30:633-8.

9. Charlson ME, Pompei P, Ales KL, Mackenzie CR. A new method of classifying prognostic comorbidity in longitudinal studies: development and validation. J Chronic Dis. 1987:40:373-83.

10. Le Gall JR, Lemeshow S, Saulnier F. A new simplified acute physiology score (SAPS II) based on a European/North American multicenter study. JAMA. 1993;270:2957-63.

11. Vincent JL, Moreno R, Takala J, Willatts S, De Mendonca A, Bruining H, et al. The SOFA (sepsis-related organ failure assessment) score to describe organ dysfunction/failure. Intensive Care Med. 1996:22:707-10.

12. Mouly S, Ruimy R, Launay $O$, Arnoult F, Brochet E, Trouillet JL, et al. The changing clinical aspects of infective endocarditis: descriptive review of 90 episodes in a French teaching hospital and risk factors for death. J Infect. 2002;45:246-56.

13. Habib G, Hoen B, Tornos P, Thuny F, Prendergast B, Vilacosta I, et al. Guidelines on the prevention, diagnosis, and treatment of infective endocarditis (new version 2009): the task force on the prevention, diagnosis, and treatment of infective endocarditis of the European Society of Cardiology (ESC). Endorsed by the European Society of Clinical Microbiology and Infectious Diseases (ESCMID) and the International Society of Chemotherapy (ISC) for Infection and Cancer. Eur Heart J. 2009;30:2369-413.

14. Selton-Suty C, Célard M, Le Moing V, Doco-Lecompte T, Chirouze C, lung $B$, et al. Preeminence of Staphylococcus aureus in infective endocarditis: a 1-year population-based survey. Clin Infect Dis. 2012. doi:10.1093/cid/ cis199.

15. Hoen B, Alla F, Selton-Suty C, Béguinot I, Bouvet A, Briançon S, et al. Changing profile of infective endocarditis: results of a 1-year survey in France. JAMA. 2002;288:75-81.

16. Hasbun R, Vikram HR, Barakat LA, Buenconsejo J, Quagliarello VJ. Complicated left-sided native valve endocarditis in adults: risk classification for mortality. JAMA. 2003;289:1933-40.
17. Akinosoglou K, Apostolakis E, Marangos M, Pasvol G. Native valve right sided infective endocarditis. Eur J Intern Med. 2013. doi:10.1016/j. ejim.2013.01.010.

18. Habib G, Lancellotti P, Antunes MJ, Bongiorni MG, Casalta JP, Del Zotti F, et al. ESC Guidelines for the management of infective endocarditis. Eur Heart J. 2015. doi:10.1093/eurheartj/ehv319.

19. Wolff M, Witchitz S, Chastang C, Régnier B, Vachon F. Prosthetic valve endocarditis in the ICU. Prognostic factors of overall survival in a series of 122 cases and consequences for treatment decision. Chest. 1995;108:688-94.

20. Wang A, Pappas P, Anstrom KJ, Abrutyn E, Fowler VG Jr, Hoen B, et al. The use and effect of surgical therapy for prosthetic valve infective endocarditis: a propensity analysis of a multicenter, international cohort. Am Heart J. 2005;150:1086-91

21. Cabell CH, Abrutyn E, Fowler VG Jr, Hoen B, Miro JM, Corey GR, et al. Use of surgery in patients with native valve infective endocarditis: results from the International Collaboration on Endocarditis Merged Database. Am Heart J. 2005;150:1092-8.

22. Aksoy O, Sexton DJ, Wang A, Pappas PA, Kourany W, Chu V, et al. Early surgery in patients with infective endocarditis: a propensity score analysis. Clin Infect Dis. 2007;44:364-72.

23. Lalani T, Cabell CH, Benjamin DK, Lasca O, Naber C, Fowler VG Jr, et al. Analysis of the impact of early surgery on in-hospital mortality of native valve endocarditis: use of propensity score and instrumental variable methods to adjust for treatment-selection bias. Circulation. 2010. doi:10.1161/CIRCULATIONAHA.109.864488.

24. Thuny F, Beurtheret S, Mancini J, Gariboldi V, Casalta JP, Riberi A, et al. The timing of surgery influences mortality and morbidity in adults with severe complicated infective endocarditis: a propensity analysis. Eur Heart J. 2011. doi:10.1093/eurheartj/ehp089.

25. Bannay A, Hoen B, Duval X, Obadia JF, Selton-Suty C, Le Moing V, et al. The impact of valve surgery on short- and long-term mortality in left-sided infective endocarditis: do differences in methodological approaches explain previous conflicting results? Eur Heart J. 2011. doi:10.1093/ eurheartj/ehp008.

26. Fowler VG Jr, Miro JM, Hoen B, Cabell CH, Abrutyn E, Rubinstein E, et al. Staphylococcus aureus endocarditis: a consequence of medical progress. JAMA. 2005;293:3012-21.

27. Fayad G, Vincentelli A, Leroy G, Devos P, Amr G, Prat A, et al. Impact of antimicrobial therapy on prognosis of patients requiring valve surgery during active infective endocarditis. J Thorac Cardiovasc Surg. 2014. doi:10.1016/j.jtcvs.2012.10.019.

\section{Submit your manuscript to a SpringerOpen ${ }^{\odot}$ journal and benefit from:}

- Convenient online submission

Rigorous peer review

- Immediate publication on acceptance

- Open access: articles freely available online

- High visibility within the field

- Retaining the copyright to your article

Submit your next manuscript at $>$ springeropen.com 